\title{
Gestão do conhecimento e redesenho de processos de negócio: proposta de uma metodologia integrada
}

\section{Valter Moreno}

\begin{abstract}
Professor de Sistemas de Informação, Gestão de Processos e Métodos Quantitativos das Faculdades Ibmec-RJ. Ph.D. em Administração pela University of Michigan (2001), Mestre em Engenharia de Produção pela Universidade Federal Fluminense - UFF (1993), e bacharel em Engenharia Eletrônica pelo Instituto Tecnológico de Aeronáutica - ITA (1988).
\end{abstract}

Lucia Helena Andrade dos Santos

Mestre em Administração de Empresas pelas Faculdades Ibmec-RJ, Pós-graduada em Filosofia Contemporânea e Didática do Ensino Superior pela PUC-RJ, Administradora pela Universidade Cândido Mendes e Tecnóloga em Processamento de Dados pela PUC-RJ.

Na última década, diversas abordagens voltadas à Gestão do Conhecimento (GC) foram desenvolvidas e aplicadas, visando aprimorar a geração, armazenagem, transferência e reutilização de conhecimentos. Contudo, vários projetos deixam de gerar os benefícios esperados, devido à distância entre as atividades orientadas à GC e as que constituem a rotina dos colaboradores da organização, como parte de seus processos de negócio. Este artigo parte da ideia de que a aproximação das práticas de GC e das rotinas organizacionais vem se tornando essencial para o sucesso das empresas, propondo uma metodologia integrada de revisão de processos e gestão do conhecimento. Para tanto, são analisados alguns dos principais modelos de GC, identificando-se as tarefas essenciais à eficaz gestão do conhecimento. Em seguida, avalia-se a compatibilidade entre essas tarefas e os procedimentos definidos nas principais metodologias de redesenho de processos. Com base nesta análise, delineia-se uma metodologia de redesenho que integra os princípios e técnicas dos dois tipos de iniciativa. A adoção dessa metodologia na condução de projetos deverá gerar processos de negócio mais equilibrados, que proporcionem uma operação eficiente e de baixo custo para empresa, ao mesmo 
tempo em que sistematizem as atividades de geração, armazenagem, transferência e reuso de conhecimento.

Palavras-chave: Gestão do Conhecimento; Processos de Negócio; Gestão de Processos; BPM.

\section{Knowledge Management and Business Process Redesign: An Integrated Framework}

In the last decade, several Knowledge Management (KM) frameworks have been developed and applied to improve creation, storage, transfer and reuse of knowledge. However, a number of projects have failed to generate the expected benefits due to a gap between KM activities and those that constitute the routines of an organization, as defined in its business processes. This paper draws on the idea that the association of $K M$ practices and organizational routines is essential to companies' success nowadays to put forth an integrated process redesign and knowledge management methodology. With this goal, some of the foremost KM frameworks were analyzed to identify the tasks that are essential to the effective management of organizational knowledge. Then, the compatibility between such tasks and the procedures defined by major process redesign methodologies were evaluated. This analysis supported the elaboration of a revised methodology that integrates the principles and techniques of both types of initiatives. The adoption of the proposed methodology should elicit the creation of business processes that harmonize an efficient, low cost operation and the systematization of an organization's knowledge creation, storage, transfer and reuse activities.

Keywords: Knowledge Management; Business Processes; Business Process Management, BPM.

Recebido em 13.05.2011 Aceito 25.01.2012

\section{Introdução}

No início do século XXI, testemunhamos a crescente valorização de um novo fator de produção: o conhecimento. A criação, armazenagem, transferência e reuso do conhecimento são, hoje, vistos como aspectos 
estratégicos importantes no âmbito das organizações, uma vez que o valor de produtos e serviços depende cada vez mais do grau em que a inovação e a inteligência são incorporadas a eles (ZACK, 2003). Desse modo, a competitividade de uma empresa vem se tornando função da sua capacidade de criar, transferir, e reutilizar conhecimentos que sejam relevantes para a sua atividade-fim (NONAKA, 1991).

Ao mesmo tempo, observamos que, com o aumento da competição e das incertezas no ambiente de negócios, várias empresas vêm tentando desenvolver uma visão holística de seus processos, sistemas, estruturas, e competências, que as permita responder de forma mais rápida e efetiva às demandas impostas pelos elementos do ambiente externo (e.g., clientes, fornecedores, concorrentes, economia, governo) (DAVENPORT; SHORT, 1990; HAMMER, 1990). Tal perspectiva tem por base a revisão/elaboração e implantação de estratégias, estruturas e processos organizacionais alinhados não apenas entre si, como, também, ao contexto externo da organização. A visão orientada para os processos de negócio tem permitido que as empresas se concentrem nos seus mercados-alvos, aumentem sua flexibilidade, e obtenham melhorias de desempenho operacional significativas, aumentando, assim, sua competitividade (GONÇALVES, 2000).

Pode-se dizer que a ênfase em processos de negócio como foco de intervenções, visando à melhoria do desempenho organizacional, tem suas origens nas teorias do movimento da Qualidade, difundido nas décadas de 70 e 80 . Nos anos 90 , as metodologias de redesenho de processos de negócio (Business Process Redesign (BPR)) ganharam notoriedade, especialmente por contraporem a necessidade de mudanças radicais ao conceito de melhorias incrementais da Gestão da Qualidade Total (Total Quality Management (TQM)) (DAVENPORT; SHORT, 1990; HAMMER, 1990; cf. BALDAN et al., 2007). Dentre as várias abordagens de BPR que surgiram, destacam-se aquelas que condicionavam o desenho dos processos às estratégias das organizações (cf. HARRINGTON, 1991; KETTINGER et al., 1997; EL SAWY, 2001). A partir de 1995, com o avanço da Internet, começaram a surgir abordagens mais específicas que tratavam da revisão de processos de negócio, com o objetivo de integrar uma empresa aos outros elos de sua cadeia de suprimento (e.g., EL SAWY, 2001). Nos últimos anos, novas propostas vêm tomando forma, contemplando principalmente o uso da Tecnologia da Informação no suporte ao gerenciamento de processos de negócio (Business Process Management (BPM)) (e.g., CRUZ, 2008; DE SORDI, 2005; LAURINDO; ROTONDARO, 2006) e o gerenciamento do conhecimento mais efetivo nos processos das organizações (EL SAWY; JOSEFEK, 2003; PATNAYAKUNI; RUPPEL; RAI, 2006; RIEGE; O'KEEFFE, 2007; SILVA; ROZENFELD, 2007; SMITH; MCKEEN, 2004). Desta forma, a necessidade de criar e gerir 0 conhecimento nas empresas começa a assumir um papel importante na implantação de mudanças em seus processos de negócio. 
Entretanto, há, ainda, uma grande distância entre os conceitos de otimização de processos encontrados nas metodologias de BPR e as propostas de modelos para a gestão do conhecimento (SMITH; MCKEEN, 2004). Enquanto isso ocorrer, perde-se a chance de utilizar os altos investimentos em BPR para criar procedimentos operacionalmente otimizados que já incluam mecanismos para obtenção, armazenagem, difusão e reuso de conhecimento nas organizações. Essa questão é também importante em função dos casos de fracasso de projetos de redesenho de processos, que demonstram que as metodologias de BPR precisam considerar os prováveis impactos de sua aplicação sobre os capitais do conhecimento e ativos intangíveis das organizações (pessoas, processos, estruturas e tecnologias). Em geral, visando obter um melhor desempenho da empresa, as metodologias de BPR concentram-se nas táticas e técnicas de redução de custos, tempo, erros e no melhor aproveitamento de recursos tangíveis. Assim, elas normalmente deixam de lado os ativos intangíveis que estão associados ao conhecimento presente nas competências das pessoas, nas estruturas organizacionais, e nos relacionamentos. Um enfoque limitado à eficiência operacional dos processos organizacionais pode até mesmo destruir o valor associado a tais ativos intangíveis (SCARBROUGH, 1998). Este efeito é ainda mais danoso quando se considera que, ao contrário do que ocorre com os ativos tangíveis, o valor dos ativos intangíveis tende a aumentar com 0 seu uso (EDVINSSON; MALONE, 1998; STEWART, 1998; SVEIBY, 1998).

A integração da Gestão do Conhecimento (Gestão do Conhecimento (GC)) aos processos de negócio visa não apenas proteger os ativos intangíveis de uma organização, como, também, desenvolvê-los e aproveitá-los, estimulando a criação de produtos e serviços mais ajustados às necessidades dos clientes e o aumento da competitividade da organização. Desta forma, os processos de negócio são vistos como o principal elemento de ligação entre o trabalho e competências dos membros de uma organização e os anseios de seus clientes (SMITH; MCKEEN, 2004). Tornam-se, também, instrumentos para a implantação e formalização da GC na empresa e para a concretização de seus potenciais benefícios (EL SAWY; JOSEFEK, 2003).

Apesar do exposto acima, a literatura acadêmica ainda carece de trabalhos com foco na relação entre $\mathrm{GC}$ e a visão de processos (OLIVEIRA et al., 2010; PATNAYAKUNI; RUPPEL; RAI, 2006, p. 547; SILVA; PEREIRA, 2006; SILVA; ROZENFELD, 2007, p. 148). O presente estudo pretende contribuir para a construção de uma base de conhecimento consistente sobre esse tema, investigando de forma criteriosa e sistemática a possibilidade de integração dos conceitos e métodos da Gestão do Conhecimento às técnicas de redesenho de processos de negócio abordadas em BPR. Inicialmente, descrevemos alguns dos principais modelos de GC que vêm orientando a prática da gestão do conhecimento (EDVINSSON; MALONE, 1998; NONAKA, 1991, 1994; STEWART, 1998; SVEIBY, 1998). A partir deles e da literatura de GC, identificamos as 
tarefas indispensáveis para a adoção efetiva da Gestão do Conhecimento nas empresas. Em seguida, analisamos a compatibilidade destas tarefas com as tradicionais táticas de redesenho de processos, sintetizadas em uma das mais completas metodologias de BPR disponíveis na literatura, proposta por El Sawy (2001). Ao final, destacamos os passos e atividades a serem inseridas na mesma metodologia, para que os processos elaborados através de sua aplicação incluam as condições necessárias para a efetiva Gestão do Conhecimento. Espera-se que a integração dos conceitos de BPR e GC e a elaboração de uma metodologia unificada possam contribuir, tanto para o desenvolvimento de processos de negócio mais eficazes quanto para a implantação da GC nas empresas, de forma mais consistente e sistemática.

\section{Princípios e modelos da gestão do conhecimento}

O conhecimento vem sendo tratado na literatura de várias formas diferentes. Alguns autores, por exemplo, o veem como um objeto, que pode ser armazenado e manipulado, ou como um processo, no qual conhecer e agir estão intrinsecamente relacionados (ALAVI; LEIDNER, 2001). Em um dos principais trabalhos da área de GC, Nonaka (1991, 1994) utilizou os conceitos da tradição filosófica japonesa para definir conhecimento como um processo humano dinâmico, objetivando justificar crenças pessoais em relação às verdades estabelecidas. Baseados nas ideias de Polanyi (1966), o mesmo autor distinguiu duas formas de conhecimento: o tácito e o explícito. Para Nonaka, o conhecimento tácito está intimamente ligado aos modelos mentais, concepções, e ações de uma pessoa, sendo frequentemente específico a um determinado contexto histórico-social. Por esta razão, o conhecimento tácito é difícil de expressar, codificar e transferir. Já o conhecimento explícito é aquele de fácil identificação e codificação, sendo geralmente expresso em técnicas, métodos, padrões, etc. É importante notar que o conhecimento está em constante mutação, sendo interpretado, validado e revalidado nos resultados das ações em que é investido (NONAKA, 1991; SVEIBY, 1998).

Recentemente, a Gestão do Conhecimento surgiu como um conjunto de conceitos, métodos e atividades que buscam atribuir valor aos chamados ativos intangíveis (capitais do conhecimento ou capital intelectual) e aumentar a capacidade de criação, armazenagem, recuperação, transferência e reutilização do conhecimento nas empresas. Os projetos de GC geralmente possuem três intenções (DAVENPORT; PRUSAK, 1998): (1) tornar o conhecimento mais visível e descrever como é aplicado nas organizações, por meio de mapas, páginas amarelas e hipertextos; (2) desenvolver uma cultura que estimule o compartilhamento de conhecimentos e a ação proativa de procura e reutilização do conhecimento; e (3) construir a infraestrutura do conhecimento, não só com sistemas e tecnologias, mas, também, na formação de uma rede de conexões entre as pessoas, encorajando-as e 
dando-Ihes espaço, tempo e ferramentas para que colaborem e compartilhem experiências, informações e conhecimentos.

Muitas das metodologias de GC têm por fundamento o processo de criação do conhecimento definido por Nonaka (1991; 1994). Ele se baseia em quatro modos de conversão entre conhecimento tácito e explícito, a saber: (1) a socialização em grupos de trabalho, nos quais ocorre a troca de conhecimentos tácitos; (2) a externalização, na qual o conhecimento tácito é expresso e codificado, transformando-se em conhecimento explícito; (3) a combinação, em que novos e antigos conhecimentos explícitos são combinados e transferidos; e (4) a internalização, na qual os novos conhecimentos explícitos são apropriados pelo indivíduo, transformando-se em conhecimento tácito. Segundo Nonaka, o processo de criação de conhecimento é composto por cinco fases: (a) o compartilhamento de conhecimento tácito; (b) a criação de conceitos; (c) a justificação dos conceitos; (d) a construção de um arquétipo ou modelo; e (e) a difusão interativa do conhecimento.

Alguns autores (e.g., EDVINSSON; MALONE, 1998; STEWART, 1998; SVEIBY, 1998) entendem que o conhecimento gerado e/ou adquirido e efetivamente mantido por uma organização é representado pelo seu conjunto de capitais do conhecimento (ou capital intelectual), o qual reflete: (1) os talentos e competências dos seus funcionários (capital humano); (2) a eficácia dos seus sistemas e processos gerenciais, sua cultura, patentes e outros conceitos e modelos desenvolvidos (capital estrutural); e (3) o caráter de seus relacionamentos com clientes, fornecedores, etc., a força de suas marcas, e sua reputação ou imagem (capital de relacionamento). É importante notar que, embora o capital humano e o capital de relacionamentos sejam as principais fontes de inovação ou renovação nas organizações, eles não garantem, por si só, que uma empresa atue de forma inteligente. Para "alavancar" o conhecimento, compartilhá-lo e transmiti-lo, é preciso ter ativos estruturais, como sistemas de informação, laboratórios, e inteligência competitiva e de mercado. O capital estrutural é responsável por dar condições ao capital humano e de relacionamentos para que agreguem valor à empresa (EDVINSSON; MALONE, 1998; STEWART, 1998).

Para que seja eficaz, a gestão do conhecimento em uma empresa deve incluir mecanismos para selecionar e cultivar ativos do conhecimento que estejam alinhados aos seus objetivos estratégicos. Deve, ainda, investir simultaneamente nas três formas de capital intelectual, para que estas se apoiem mutuamente (STEWART, 1998). Como explicado anteriormente, a obtenção de vantagem competitiva depende da interrelação e sinergia entre o capital humano, de relacionamentos, e estrutural.

No que tange ao capital humano, Stewart (1998) sugere que, primeiramente, se identifiquem as competências que sejam específicas ao 
negócio e que realmente agreguem valor para empresa, e as que possam ser adquiridas facilmente. A riqueza organizacional é criada por meio da aplicação de habilidades e talentos proprietários e/ou estratégicos, que gera o valor pelo qual os clientes pagam. Por isso, as pessoas com estes talentos são ativos nos quais se deve investir. Deve-se, então, criar instrumentos, como os mapas de competência, comunidades de prática, e outras formas de socialização do aprendizado (STEWART, 1998), em que as competências proprietárias e estratégicas para a empresa possam ser identificadas, acessadas, cultivadas, e transferidas. Adicionalmente, é importante definir como a organização pode se beneficiar do aumento do capital humano, pois a empresa pode perder seus funcionários inesperadamente. Um problema comum é manter os profissionais que chegam ao ápice de suas carreiras motivados e satisfeitos, já que eles normalmente desejam continuar a realizar atividades criativas e projetos desafiadores (SVEIBY, 1998). Sveiby (1998) sugere que se estabeleçam atividades e formas de compensação alternativas, tais como cursos de aperfeiçoamento ou uma posição acadêmica em tempo parcial.

Stewart (1998) argumenta que o capital de relacionamentos pode ser desenvolvido por meio: (1) da disponibilização de informações relevantes para os clientes; (2) da otimização da cadeia de valor intangível (que informações impulsionam o negócio? quem as tem? para quem elas valem mais?); (3) de programas de parceria e inovação conjunta, com a divisão de benefícios e responsabilidades; e (4) do atendimento das necessidades específicas de cada cliente. Por outro lado, o desenvolvimento do capital estrutural exige: (1) que se obtenham os recursos necessários para desenvolver estoques de conhecimento; (2) que se identifiquem os conhecimentos que devem ser armazenados; (3) que se acelerem os fluxos de transferência de conhecimento na empresa; e (4) que se equilibre $o$ acesso às informações e a obtenção do conhecimento especializado. Com relação à transferência de conhecimento, deve-se enfatizar a importância do uso de sistemas de troca de informações baseados em computadores e da formalização de mecanismos na organização voltados à exteriorização e codificação do conhecimento (ALAVI; LEIDNER, 2001; SVEIBY, 1998). Stewart (1998) ressalta, também, que, embora o capital estrutural seja o ativo intangível que as empresas efetivamente possuem e podem controlar, ele é o que menos importa ao cliente final. O capital estrutural serve para acumular estoques de conhecimento que sustentem o trabalho que os clientes valorizam e para acelerar o fluxo de informação dentro da empresa. Vale ressaltar que, apesar de sua importância, as iniciativas e metodologias de GC geralmente deixam de lado os aspectos relativos à transformação dos processos de negócio da empresa (SMITH; MCKEEN, 2004). Conforme destacado a seguir, a otimização desses processos é o tema fundamental das metodologias de BPR. 


\section{Princípios e metodologias de redesenho de processos de negócio (BPR)}

Segundo Hammer (1990; cf. HAMMER; CHAMPY, 1994; HAMMER; STANTON, 1999), a reengenharia ou redesenho de processos de negócio (BPR) consiste no repensar profundo e reestruturação radical de um processo, capazes de provocar melhorias significativas nos indicadores de desempenho das organizações, em termos de custo, qualidade, serviço, e velocidade. A essência de um projeto de reengenharia é a identificação e a quebra de regras e fundamentos ultrapassados que ainda orientam as operações de uma empresa (DAVENPORT, 1993; EL SAWY, 2001; KETTINGER et al., 1997). Hammer destaca, também, que a qualidade, a inovação e o serviço são mais importantes do que o custo e os controles financeiros e que, por isso, a integração entre os diversos processos operacionais é fundamental para o sucesso de uma empresa.

Davenport e Short (1990) veem a Tecnologia da Informação (TI) como componente fundamental na reestruturação estratégica dos processos de negócio e não apenas como uma forma de automatização e mecanização de procedimentos. Isto porque as atividades de negócio não devem ser consideradas isoladamente e, sim, como elementos básicos de processos de negócio horizontais mais amplos, ou seja, como componentes inter-relacionados de um fluxo de trabalho (GONÇALVES, 2000). Portanto, uma visão orientada para processos vai além das atividades executadas dentro de um único departamento: ela deve também contemplar o fluxo de produtos, serviços, e informações entre departamentos (e.g., DAVENPORT, 1993; DAVENPORT; SHORT, 1990; GONÇALVES, 2000; EL SAWY, 2001; RUMMLER; BRACHE，1994).

Em última análise, todas as metodologias de BPR buscam maximizar o valor adicionado por um processo de negócio (EL SAWY, 2001). Este valor pode ser avaliado por meio de medidas de desempenho (e.g., rapidez, produtividade, custo, satisfação dos clientes) e retorno sobre investimento (ROI). Para alcançar esse objetivo, as metodologias de BPR geralmente definem cinco estágios para execução de um projeto de redesenho de processos (DAVENPORT, 1993; KETTINGER et al., 1997; EL SAWY, 2001): (1) desenvolvimento da visão estratégica do negócio e de objetivos compatíveis para os processos de negócio da empresa; (2) mobilização de recursos e pessoas para a execução do projeto de redesenho; (3) análise e redesenho dos processos; (4) implantação dos novos processos e ajuste da organização; e (5) acompanhamento do desempenho e refinamento dos novos processos. Deve-se ressaltar que um projeto de redesenho envolve mudanças não apenas em processos de negócio, mas, também, em tecnologias, nas competências das pessoas e trabalho que executam e na estrutura e cultura organizacionais. Por essa razão, demandam equipes de projeto multidisciplinares muito bem coordenadas (HAMMER, 1990; DAVENPORT, 1993). O quarto estágio 
definido acima, reflete justamente esta necessidade de se contemplar e integrar os diversos elementos do sistema organizacional em projetos de $B P R$, para que se possa efetivamente atingir os resultados esperados (EL SAWY, 2001; KETTINGER et al., 1997).

Tendo por base um amplo estudo da literatura de redesenho e gerenciamento de processos e das práticas observadas nas empresas, El Sawy (2001) sugere que todas as metodologias de BPR se baseiam em um princípio comum: a minimização do "lixo" (trabalho que não agrega valor para o cliente do processo), por meio da eliminação de atividades obsoletas, da consolidação de atividades similares, e da simplificação de procedimentos. O autor argumenta que esse objetivo pode ser alcançado ajustando-se a topologia dos fluxos associados a um processo de negócio, sejam eles relativos ao movimento de produtos físicos, à transmissão de informação ou à geração, armazenagem e difusão do conhecimento.

Paradoxalmente, a literatura de BPR é bastante deficiente em relação, quando trata das tarefas de redesenho de processos em si. Pouco se sabe sobre como as atividades associadas ao terceiro estágio de um projeto de BPR devem ser (e são) efetivamente executadas (cf. HAMMER; CHAMPY, 1994; KETTINGER et al., 1997). O trabalho de El Sawy (2001) é, na realidade, um dos poucos que tratam deste assunto. Nele, o autor define uma série de princípios e táticas que podem ser utilizados para direcionar a criação ou redesenho de processos de negócio. Tais táticas devem ser entendidas como possíveis tarefas de redesenho, e não regras inflexíveis a serem implantadas em todo e qualquer caso. Para efeito de comparação, as táticas definidas por El Sawy (2001) são descritas em conjunto com as orientações propostas por Hammer (1990) e Harrington (1991), nos quadros que se seguem.

Quadro 1 - Princípios de redesenho

1. Organize as funções e cargos envolvidos no processo em torno dos resultados e não das tarefas executadas.

2. Transfira atividades do processo para aqueles que utilizam os seus resultados.

3. Integre as atividades de processamento e produção de informações.

4. Trate os recursos dispersos geograficamente como se estivessem centralizados.

5. Integre atividades paralelas, em vez de integrar seus resultados.

6. Coloque o ponto de decisão onde o processo é executado e construa o controle dentro do processo.

7. Capture a informação uma só vez, na sua fonte.

Fonte: HAMMER (1990). 


\section{Quadro 2 - Princípios de redesenho}

1. Elimine atividades duplicadas.

2. Avalie o valor agregado pelas atividades e elimine as que não agregarem valor.

3. Reduza a complexidade do processo.

4. Reduza o tempo de ciclo do processo.

5. Crie mecanismos para detectar e reduzir a ocorrência de erros.

6. Atualize competências dos recursos humanos e modernize instalações e equipamentos.

7. Use uma linguagem simples nas comunicações, formulários e relatórios.

8. Padronize atividades.

9. Crie parcerias com fornecedores.

10. Use a criatividade para gerar melhorias substanciais no processo.

11. Automatize e/ou mecanize tarefas.

12. Elimine a burocracia.

Fonte: HARRINGTON (1991).

\section{Quadro 3 - Princípios e táticas de redesenho}

1. Diminua o tempo de espera.

a. Redesenhe tarefas executadas sequencialmente para que sejam executadas em paralelo.

b. Crie equipes autossuficientes que tenham interação mais rápida e flexível.

c. Não permita que tarefas de suporte ou gerência bloqueiem a execução de um processo que agregue valor e o atrasem.

d. Desenhe o fluxo de forma contínua, evitando o processamento em lotes.

e. Modifique práticas no início do processo para evitar gargalos no final do processo.

2. Orquestre a execução.

a. Crie parcerias com outras empresas.

b. Avalie a possibilidade de terceirizar atividades e processos.

c. Caso seja mais rápido e barato, retome atividades e processos que haviam sido terceirizados.

d. Utilize mercados eletrônicos e mecanismos similares na Web para gerenciar fornecedores e parceiros.

3. Customize em massa.

a. Flexibilize o acesso ao processo, aumentando o tempo em que ele opera e/ou usando ferramentas de comércio eletrônico.

b. Flexibilize o acesso ao processo por meio da ampliação e/ou "virtualização" do espaço físico em que ele ocorre.

c. Crie plataformas de processo modulares que consistam de módulos independentes.

d. Leve as atividades de customização para perto do cliente, isto é, próximo ao final do processo.

e. Viabilize a customização dinâmica dos produtos do processo.

4. Sincronize.

a. Case as ofertas de produto nos canais físicos e virtuais.

b. Crie plataformas comuns aos processos físicos e eletrônicos.

c. Monitore eletronicamente o movimento de produtos físicos na empresa.

5. Digitalize e propague as informações.

a. Passe a responsabilidade pela entrada digital de dados ao cliente, na entrada do processo.

b. Elimine o uso de papel no processo.

c. Torne a informação acessível a todos.

d. Diminua a distância entre as informações necessárias às decisões no processo e os pontos onde elas são tomadas. 
6. Vitrifique o andamento do processo.

a. Permita que o andamento do processo seja monitorado por seus clientes.

b. Viabilize a geração de relatórios e análises do processo em tempo real.

c. Desenhe processos que façam a interface com os parceiros para a troca de informações.

7. Torne o processo "sensível".

a. Introduza mecanismos de realimentação que captem a visão dos clientes para detectar disfunções do processo.

b. Crie mecanismos nos sistemas de TI que permitam à empresa reagir rapidamente às mudanças.

c. Integre sensores ambientais ao processo para monitorar mudanças.

8. Analise e sintetize.

a. Use ferramentas para análise de cenários para melhorar a tomada de decisão.

b. Use ferramentas para a análise iterativa de dados que detectem padrões de demanda e de execução do processo.

c. Use ferramentas para integrar várias fontes de informação.

9. Conecte, colete e crie.

a. Crie uma comunidade de prática para o processo.

b. Mapeie áreas de especialidade e crie um diretório de especialistas relacionados ao processo.

c. Estabeleça repositórios de conhecimento que possam ser reutilizados para a melhoria do desempenho do processo.

d. Desenvolva um banco de dados de perguntas mais frequentes (FAQ) dos executores do processo.

e. Crie espaços ao longo do processo para a troca de informações e experiências.

10. Personalize.

a. Entenda as preferências dos clientes e dos que executam o processo e utilize-as para definir perfis (ou padrões).

b. Insira regras de negócio no processo que sejam acionadas de acordo com o perfil das pessoas.

c. Use técnicas automatizadas de filtragem colaborativa para comparar perfis de pessoas.

d. Monitore os hábitos pessoais dos clientes e funcionários que executam o processo.

Fonte: EL SAWY (2001).

As orientações dos três autores sinalizam pontos ou aspectos a serem examinados no processo que é objeto do projeto de redesenho, havendo, certamente, similaridades entre elas. Por exemplo, o princípio 7 de Hammer é similar à tática 5.a de El Sawy; por sua vez, a tática 5.b de El Sawy pode ser vista como uma forma de implementar o princípio 12 de Harrington. Entretando, observa-se que o grupo de princípios e táticas delineados por El Sawy é o mais abrangente e detalhado, contemplando, inclusive, os pontos abordados pelos outros dois autores. Por essa razão, as análises aqui realizadas se concentraram nas táticas definidas por El Sawy. A seguir, descrevemos como elas foram conduzidas.

\section{Metodologia}

Para atingir os objetivos anteriormente propostos, adotou-se, neste estudo, um método hipotético-dedutivo (DANE, 1990) similar ao utilizado por autores, como Smith e McKeen (2004) e Silva e Rozenfeld (2007). Em linhas gerais, teorias, conceitos e resultados empíricos encontrados na literatura foram criticamente analisados e confrontados entre si, de forma iterativa, visando eliminar resultados espúrios ou pouco significativos e reter os elementos comuns essenciais para a construção de uma 
metodologia que integrasse os preceitos de BPR e GC. As propostas que resultavam desse processo eram também avaliadas e ajustadas em ciclos sucessivos, como previsto em métodos hipotético-dedutivos.

Primeiramente, identificamos as tarefas essenciais a uma gestão do conhecimento eficaz. Isto foi feito por meio da análise dos modelos de GC discutidos anteriormente e da avaliação de fatores críticos de sucesso (FCS) descritos na literatura. O exame dos FCS da GC teve por objetivo revelar elementos do sistema organizacional que fossem indispensáveis para uma gestão do conhecimento bem sucedida e que pudessem ser viabilizados por meio de tarefas executadas ao longo de projetos de redesenho de processos de negócio.

Em seguida, avaliamos a relação e compatibilidade das tarefas previamente identificadas com as táticas de BPR definidas por El Sawy (2001). Nessa etapa, procuramos compreender como o conjunto de tarefas da gestão de conhecimento poderia complementar (ou não) o conjunto de táticas de BPR. Cinco situações foram identificadas:

tarefas de GC e táticas de BPR poderiam ser equivalentes, ou seja, as atividades e funções que nelas estão envolvidas, assim como os resultados que deveriam gerar, são basicamente os mesmos;

a) uma tarefa de GC pode ser indispensável para a implantação de uma tática de redesenho, e vice-versa. Neste caso, elas apresentam níveis elevados de interdependência, uma antecedendo necessariamente a outra, como précondição para a sua realização;

b) uma tarefa de GC pode contribuir para a implantação de uma tática de BPR, mas não ser indispensável para a sua realização. Teriam, portanto, um nível médio de interdependência, embora a relação de antecedência não estivesse bem definida;

c) tarefas de GC poderiam não ter relação direta com as táticas de BPR, e vice-versa. Deste modo, não há relação de dependência ou antecedência temporal entre elas; e

d) tarefas de GC e as táticas de BPR poderiam estar em conflito. Em tais situações, a realização de uma tarefa poderia dificultar a implantação de uma tática, e vice-versa. Neste caso, dever-se-ia encontrar uma solução para o conflito, examinando prioridades e modos alternativos de gerar os resultados esperados.

Para realizar a análise, montou-se uma tabela, onde as linhas representavam as táticas de $\mathrm{BPR}$, e as colunas, as tarefas de GC. Os autores deste trabalho, ambos com considerável experiência nas áreas de redesenho de processos e gestão do conhecimento, avaliaram 
separadamente cada relação entre tarefa e tática na tabela, inserindo uma notação na célula correspondente, para representar sua a conclusão sobre a compatibilidade e complementaridade de cada par. As notações definidas foram: "E" para uma relação de equivalência; "I", para uma relação de indispensabilidade; "C" para uma relação de contribuição; "-" para uma relação de independência; e " $X$ " para uma relação de conflito.

Em seguida, as avaliações individuais dos dois autores foram comparadas em conjunto. As poucas discrepâncias encontradas foram discutidas e sanadas. A avaliação final conjunta foi novamente analisada, com o intuito de definir prioridades na execução de tarefas e implantação de táticas e, ainda, de encontrar soluções para as relações de conflito. Tal análise serviu de base para a definição de como e em que estágio as tarefas relevantes de GC deveriam ser adicionadas à metodologia de BPR. $\mathrm{Na}$ execução desse último passo, foram levados em conta os seguintes fatores:

a) o tipo de relação encontrada entre a tarefa e a tática, para definir relações de antecedência temporal. As relações de equivalência não implicavam em mudanças na metodologia de $B P R$, já que as táticas existentes implementavam as tarefas de GC a elas associadas. As relações de indispensabilidade e contribuição exigiam a inclusão de atividades de GC em uma sequência específica. As relações de independência permitiam que as tarefas fossem incluídas em qualquer etapa do projeto de BPR. As relações de conflito exigiam, primeiramente, uma solução. A partir dela, examinavam-se as relações de prioridade, de acordo com o que foi descrito acima;

b) a afinidade entre tarefas e atividades de BPR. Uma vez definida a relação de antecedência entre tarefas e táticas, dever-se-ia determinar em que etapa da metodologia de redesenho cada tarefa deveria ser adicionada. Para tanto, considerou-se a afinidade da tarefa com as atividades definidas em cada etapa da metodologia. O grau de afinidade foi determinado em função da compatibilidade dos resultados da tarefa e das atividades, das pessoas envolvidas no desempenho de ambas, e da similaridade de informações e recursos necessários à sua realização. Tal análise visou minimizar a complexidade e o custo da realização das novas tarefas de GC, ao mesmo tempo em que se mantinha a sua contribuição para a gestão eficaz do conhecimento nos processos de negócio da empresa; e

c) posteriormente, as próprias tarefas de GC foram analisadas para se definir as relações de prioridade e a afinidade entre elas. Dessa forma, pode-se definir que tarefas deveriam preceder as outras dentro de um mesmo estágio da metodologia de BPR. 
O resultado final da aplicação desse procedimento de análise foi a reformulação parcial da metodologia de BPR de El Sawy (2001), com a inclusão das novas atividades para a gestão de conhecimento e a modificação de algumas táticas para torná-las compatíveis com as tarefas de GC.

\section{Tarefas essenciais da Gestão do Conhecimento (GC)}

As características do conhecimento e os modelos e princípios da Gestão do Conhecimento anteriormente descritos serviram de base para a identificação das tarefas essenciais à gestão eficaz dos capitais humano, estrutural e de relacionamentos. Adicionaram-se a tais fontes os fatores críticos de sucesso frequentemente encontrados na literatura de GC (e.g., ALAVI; LEIDNER, 2001; DAVENPORT; PRUSAK, 1998; DUFFY, 2001; GARVIN, 1993; NONAKA, 1991, 1994; SMITH; MCKEEN, 2004; ZACK, 1993). As tarefas pertinentes a projetos de BPR geradas a partir dessa análise são apresentadas abaixo, juntamente com uma breve justificativa para a sua inclusão neste estudo. As tarefas associadas ao capital humano, estrutural e de relacionamentos serão designadas pelas letras "H", "E", e "R", respectivamente.

H1: Identificar as competências proprietárias e/ou estratégicas na organização. Esta tarefa é indispensável para o investimento no capital humano (STEWART, 1998) e a criação de mapas de competência e diretórios de especialistas (ALAVI; LEIDNER, 2001; DUFFY, 2001). Ela também é essencial para o alinhamento da estratégia de GC com a estratégia de negócio da empresa, ou seja, com o seu foco e objetivos estratégicos;

H2: Eliminar tarefas irracionais, burocráticas e inúteis. Conforme sugerido por Stewart (1998), esta é uma condição necessária para aproveitar de forma ótima o conhecimento acumulado pelas pessoas na organização. O conhecimento é desperdiçado, isto é, deixa de ser aplicado de modo eficaz para a organização, quando se exige que as pessoas invistam seu tempo e energia em tarefas inúteis;

H3: Orientar e facilitar o aprendizado individual. Esta tarefa está associada à elaboração dos mapas de competência (ALAVI; LEIDNER, 2001; DUFFY, 2001; GARVIN, 1993; STEWART, 1998), que visam, também, orientar programas de treinamento para cada profissional da empresa, de acordo com suas intenções. É importante que as pessoas desenvolvam competências nas técnicas e ferramentas utilizadas na realização e avaliação de experimentos, e que seu treinamento envolva a aplicação dos novos conhecimentos em suas rotinas de trabalho (GARVIN, 1993; ZACK, 2003). Vale lembrar que se deve alocar o tempo necessário nas rotinas de trabalho para que os empregados possam refletir, analisar, discutir, e tentar aplicar novas idéias em suas atividades (ALAVI; LEIDNER, 2001; GARVIN, 1993);

H4: Criar condições para a socialização do aprendizado em grupos e em equipes de trabalho. A socialização é um processo fundamental para 
a transferência e aplicação do conhecimento tácito nas organizações (NONAKA, 1991; 1994). Além disso, ajuda a estabelecer redes de relacionamento entre as pessoas, o que é importante para a geração, localização, e transmissão de novos conhecimentos (DAVENPORT; PRUSAK, 1998; ZACK, 2003). Algumas das formas de estimulá-la são: a execução do trabalho por equipes (multifuncionais ou não), a criação de comunidades de prática e a implantação de programas de visitas a diferentes áreas da empresa e de rotação de pessoal (GARVIN, 1993; STEWART, 1998). De forma geral, comunicação e trocas colaborativas são essenciais para a criação de "um ambiente favorável a padrões de interação praticados e habituais que alavanquem o conhecimento em atividades coletivas e facilitem a integração do conhecimento entre indivíduos, grupos e outros níveis organizacionais" (PATNAYAKUNI; RUPPEL; RAI, 2006, p. 560);

H5: Aproveitar e valorizar ao máximo a capacidade de geração e aplicação de conhecimento dos profissionais. É prioritário que a organização mantenha em seus quadros as pessoas que efetivamente contribuem para a geração e aplicação de conhecimentos que gerem vantagem competitiva (SVEIBY, 1998). Para tanto, devem criar sistemas de avaliação de desempenho, incentivos e recompensas adequadas, que estimulem a criatividade e experimentação, com controle e responsabilidade (ALAVI; LEIDNER, 2001; DUFFY, 2001; GARVIN, 1993). Nonaka (1991) enfatiza que o conhecimento pode ser gerado em qualquer nível e função de uma organização, e não apenas por gerentes e técnicos especializados;

H6: Compartilhar conhecimentos estratégicos, valores e cultura com os funcionários. Nonaka $(1991 ; 1994)$ sugere que se crie uma visão para a empresa que seja aberta e capaz de suscitar uma variedade de interpretações diferentes e até mesmo conflitantes. Ao mesmo tempo, a visão deve estar alinhada aos objetivos da gestão do conhecimento, e prover um senso de direção geral e propósito para os empregados (ZACK, 2003), orientando. Ela deve orientar a elaboração de um planejamento estratégico que promova a gestão do conhecimento e estimule a criatividade e inovação na organização. O compartilhamento dessa visão estratégica e dos valores e cultura da empresa é fundamental, também, para estabelecer uma base cognitiva comum, composta por perspectivas, significados, e valores, que é indispensável para a troca de conhecimentos tácitos (ALAVI; LEIDNER, 2001; NONAKA, 1991). Além disso, estabelece critérios para avaliar o valor e legitimidade de novos conhecimentos para a organização (NONAKA, 1991);

E1: Identificar os conhecimentos necessários para as pessoas desempenharem suas atividades em um processo de negócio, de forma eficiente e eficaz. De acordo com Stewart (1998), o capital estrutural serve para acumular estoques de conhecimento que sustentem o trabalho que os clientes valorizam e para acelerar o fluxo de informação dentro da organização. O mesmo autor defende que é no fluxo de informações e não no fluxo de materiais, que está o verdadeiro negócio de uma empresa. A tarefa aqui proposta define as condições necessárias para a identificação, 
armazenagem e disseminação dos conhecimentos ao longo de um processo, para que seja capaz de gerar o valor desejado por seus clientes e contribuir para a concretização dos objetivos estratégicos da organização;

E2: Providenciar recursos para facilitar o acesso às informações e conhecimentos necessários à adequada execução dos processos. Pelas razões expostas acima, é importante que informações e conhecimentos estejam disponíveis para aqueles que desempenham as atividades de um processo de negócios. Portanto, deve-se prover os recursos físicos, financeiros, e tecnológicos e estabelecer os mecanismos necessários para que isto realmente ocorra na empresa (e.g., DUFFY, 2001; PATNAYAKUNI; RUPPEL; RAI, 2006; SILVA; ROZENFELD, 2007).

E3: Aumentar a velocidade de transmissão e distribuição de informações e conhecimento ao longo do processo. Stewart (1998) argumenta que a qualidade, rapidez e continuidade do fluxo de informações ao longo de um processo são fundamentais para a geração de valor para os seus clientes (cf. EL SAWY, 2001). São, também, essenciais como estímulo para a geração e aplicação de novos conhecimentos na organização (PATNAYAKUNI; RUPPEL; RAI, 2006; SILVA; ROZENFELD, 2007);

E4: Introduzir mecanismos nas práticas, atividades e processos da empresa de forma a tornar a geração, transferência, e uso do conhecimento uma parte da rotina de trabalho. Uma variedade de fatores sociais e organizacionais contribui para criar uma lacuna entre a obtenção de conhecimento e a sua aplicação no dia a dia das empresas (ALAVI; LEIDNER, 2001; DAVENPORT; PRUSAK, 1998; SMITH; MCKEEN, 2004). É importante, portanto, que as empresas façam da gestão do conhecimento uma parte integrante do trabalho das pessoas (PATNAYAKUNI; RUPPEL; RAI, 2006). Isto pode e deve ser feito por meio da introdução de sistemas de informação e da modificação de processos de negócio (SEELEY, 2002; SMITH; MCKEEN, 2004; ZACK, 2003), conforme sugerido neste estudo. Parte das informações a serem coletadas, codificadas e armazenadas diz respeito a experiências de sucesso e fracassos vividos pela empresa (GARVIN, 1993);

R1: Estimular a troca de ideias entre funções, departamentos, unidades de negócio. O desenvolvimento de relacionamentos entre as várias áreas da organização é considerado fundamental para melhorar o entendimento dos seus processos de negócio e das perspectivas dos seus vários colaboradores, romper com barreiras e preconceito, e estimular a inovação (GARVIN, 1993; NONAKA, 1991; PATNAYAKUNI; RUPPEL; RAI, 2006; ZACK, 2003);

R2: Estimular e facilitar a colaboração com clientes e fornecedores. Scarbrough (1998, p. 198) chama atenção para a necessidade de "complementar a adoção do paradigma horizontal dos processos de negócio com conexões laterais que permitam à firma se aproximar de redes de conhecimento externas e, portanto, incrementar a inovação em seus próprios processos". Em particular, o entendimento do valor que clientes e fornecedores dão a alguns tipos de informação é essencial para 
que se desenvolvam parcerias e mecanismos para estabelecer e manter um fluxo contínuo de informações entre as empresas (GARVIN, 1993; STEWART, 1998; ZACK, 2003). A troca de informações relevantes ao longo da cadeia de produção estimula a colaboração, e a geração, transferência e aplicação de conhecimentos de forma conjunta. Conhecendo melhor as necessidades de seus clientes e parceiros, a organização pode desenvolver novos produtos e serviços, melhorar seus processos de negócio, etc., e, assim, obter vantagem competitiva (e.g., SILVA; ROZENFELD, 2007). Por outro lado, na medida em que se permite a clientes e parceiros o acesso a informações, eles podem utilizá-las para adequar seus próprios processos, produtos e serviços, e assim contribuir para a geração de valor para o negócio da empresa.

\section{Compatibilidade entre a Gestão do Conhecimento e o redesenho de processos}

Conforme detalhado anteriormente, foi feita uma análise das relações entre as diversas tarefas associadas à gestão do conhecimento identificadas acima, e as táticas de redesenho definidas por El Sawy (2001). No total, 456 relações foram examinadas. Os resultados dessa análise são mostrados na Tabela 1 , e seguem a notação descrita anteriormente. Em seguida, são apresentados exemplos de como as relações foram avaliadas.

Tabela 1 - Resultados da análise das relações entre tarefas de GC e táticas de BPR

\begin{tabular}{c|c|c|c|c|c|c|c|c|c|c|c|c}
\hline $\begin{array}{c}\text { Táticas } \backslash \\
\text { Tarefas }\end{array}$ & $\mathbf{1}$ & $\mathbf{2}$ & $\mathbf{3}$ & $\mathbf{4}$ & $\mathbf{5}$ & $\mathbf{6}$ & $\mathbf{1}$ & $\mathbf{2}$ & $\mathbf{3}$ & $\mathbf{4}$ & $\mathbf{1}$ & $\mathbf{2}$ \\
\hline 1.1 & - & $\mathrm{C}$ & - & - & - & - & $\mathrm{C}$ & - & - & $\mathrm{C}$ & - & - \\
\hline 1.2 & $\mathrm{C}$ & $\mathrm{C}$ & - & $\mathrm{C}$ & - & - & $\mathrm{I}$ & $\mathrm{I}$ & $\mathrm{C}$ & $\mathrm{I}$ & $\mathrm{C}$ & - \\
\hline 1.3 & - & $\mathrm{C}$ & - & - & - & $\mathrm{X}$ & - & - & $\mathrm{C}$ & $\mathrm{X}$ & - & - \\
\hline 1.4 & - & - & - & - & - & - & - & - & $\mathrm{C}$ & - & - & - \\
\hline 1.5 & - & - & - & - & - & - & $\mathrm{C}$ & - & - & - & - & - \\
\hline 2.1 & $\mathrm{I}$ & $\mathrm{C}$ & - & - & - & - & $\mathrm{C}$ & - & - & - & - & - \\
\hline 2.2 & $\mathrm{I}$ & $\mathrm{C}$ & - & $\mathrm{C}$ & - & - & $\mathrm{C}$ & - & - & - & - & $\mathrm{I}$ \\
\hline 2.3 & $\mathrm{I}$ & - & $\mathrm{C}$ & - & - & - & $\mathrm{I}$ & - & - & $\mathrm{C}$ & - & - \\
\hline 2.4 & - & $\mathrm{C}$ & - & - & - & - & $\mathrm{C}$ & - & $\mathrm{C}$ & $\mathrm{C}$ & - & - \\
\hline 3.1 & - & - & - & - & - & - & $\mathrm{C}$ & - & $\mathrm{C}$ & $\mathrm{C}$ & - & - \\
\hline 3.2 & - & - & - & - & - & - & $\mathrm{C}$ & - & - & $\mathrm{C}$ & - & - \\
\hline 3.3 & - & - & - & - & - & - & $\mathrm{C}$ & - & $\mathrm{C}$ & $\mathrm{C}$ & - & - \\
\hline 3.4 & - & - & - & - & - & - & $\mathrm{C}$ & - & $\mathrm{I}$ & $\mathrm{C}$ & - & $\mathrm{C}$ \\
\hline 4.1 & - & - & - & - & - & - & $\mathrm{C}$ & - & $\mathrm{C}$ & $\mathrm{C}$ & - & - \\
\hline 4.2 & - & - & - & - & - & - & $\mathrm{C}$ & - & $\mathrm{C}$ & $\mathrm{C}$ & - & - \\
\hline 4.3 & - & - & - & - & - & - & $\mathrm{C}$ & $\mathrm{C}$ & $\mathrm{C}$ & $\mathrm{C}$ & - & - \\
\hline & & & & & & & & \\
\hline
\end{tabular}




\begin{tabular}{|c|c|c|c|c|c|c|c|c|c|c|c|c|}
\hline \begin{tabular}{l} 
Táticas \} $\\
{\text { Tarefas }}$ & $\begin{array}{l}\mathrm{H} \\
1\end{array}$ & \begin{tabular}{|l|}
$H$ \\
2
\end{tabular} & \begin{tabular}{|l|}
$\mathrm{H}$ \\
$\mathbf{3}$
\end{tabular} & $\begin{array}{l}H \\
4\end{array}$ & \begin{tabular}{|l}
$H$ \\
5
\end{tabular} & $\begin{array}{l}H \\
6\end{array}$ & $\begin{array}{l}E \\
1\end{array}$ & $\begin{array}{l}\mathrm{E} \\
2\end{array}$ & $\begin{array}{l}E \\
3\end{array}$ & $\begin{array}{l}E \\
4\end{array}$ & $\begin{array}{l}\mathrm{R} \\
1\end{array}$ & $\begin{array}{l}\mathbf{R} \\
2\end{array}$ \\
\hline 5.1 & - & - & - & - & - & - & - & 1 & C & $C$ & - & - \\
\hline 5.2 & - & - & - & - & - & - & - & C & C & C & - & - \\
\hline 5.3 & - & - & $C$ & - & - & 1 & 1 & I & C & C & C & - \\
\hline 5.4 & - & - & $C$ & - & - & - & 1 & I & C & C & - & - \\
\hline 6.1 & - & - & - & - & - & - & - & I & C & - & - & $\mathrm{I}$ \\
\hline 6.2 & - & - & C & - & - & - & C & 1 & C & C & - & - \\
\hline 6.3 & - & - & $C$ & - & - & - & - & C & - & C & - & I \\
\hline 7.1 & - & - & $C$ & - & - & - & 1 & I & C & C & - & C \\
\hline 7.2 & - & - & - & - & - & - & 1 & I & 1 & 1 & - & C \\
\hline 7.3 & - & - & $C$ & - & - & C & 1 & I & C & C & - & C \\
\hline 8.1 & - & - & $C$ & - & - & - & C & 1 & C & - & - & - \\
\hline 8.2 & - & - & $C$ & - & - & - & C & 1 & C & - & - & - \\
\hline 8.3 & $C$ & $C$ & $C$ & - & - & C & C & I & C & C & C & C \\
\hline 9.1 & I & - & $C$ & I & C & 1 & 1 & C & - & - & C & - \\
\hline 9.2 & I & C & C & - & C & - & 1 & 1 & - & $C$ & C & C \\
\hline 9.3 & $C$ & C & C & - & - & C & 1 & I & C & C & C & C \\
\hline 9.4 & C & - & C & - & - & - & C & I & C & C & C & C \\
\hline 9.5 & - & - & $\mathrm{C}$ & I & - & I & C & C & - & - & I & $\mathrm{C}$ \\
\hline 10.1 & - & - & - & - & - & - & C & 1 & $\mathrm{C}$ & - & - & C \\
\hline 10.2 & - & - & - & - & - & - & 1 & I & C & C & - & C \\
\hline 10.3 & - & - & - & - & - & - & - & I & C & C & - & $C$ \\
\hline 10.4 & - & - & - & - & - & - & C & 1 & C & C & - & C \\
\hline
\end{tabular}
\end{tabular}

Legenda:

"E" - equivalência;

"I" - indispensabilidade;

"C" - contribuição;

"-" - independência;

"X" - conflito

Fonte: Dados da pesquisa.

Como ilustração do processo de avaliação que resultou na tabela acima, tomemos primeiramente a relação de indispensabilidade (I) entre a tarefa $\mathrm{H} 1$ e as táticas de redesenho 2.1, 2.2, e 2.3. Para decidir sobre uma opção de terceirização (2.1), a criação de parcerias (2.2) ou retomar a execução de tarefas que haviam sido terceirizadas (2.3), julgamos ser imprescindível que se saiba primeiramente que competências a organização considera proprietárias e/ou estratégicas (H1). Por exemplo, 
atividades envolvendo esse tipo de competências não devem ser terceirizadas, pois se pode com isso perder vantagem competitiva. Da mesma forma, tendo com base na identificação dessas competências, a empresa pode investir na criação de parcerias para tentar desenvolver ou obter aquelas que lhe faltem. Por outro lado, não parece recomendável retomar atividades que não envolvam competências proprietárias e/ou estratégicas, uma vez que não gerariam diferencial competitivo para a empresa (INSINGA; WERLE, 2000).

O mesmo tipo de relação existe entre a tarefa $\mathrm{E} 1$ e a tática 1.2. A definição das pessoas que irão compor um time autossuficiente (1.2) exige que se identifique, antes de qualquer coisa, os conhecimentos que são necessários para se desempenhar as atividades alocadas ao time. Notamos, também, que a tarefa $\mathrm{H} 1$ contribui (C) para a implantação desta mesma tática de BPR (1.2), não sendo, no entanto, indispensável. Isto porque, em alguns casos, pode ser necessário incluir pessoas com competências proprietárias ou estratégicas num time, enquanto que em outros, não. A relação de contribuição se inverte no caso da tarefa $\mathrm{H} 2$ e das táticas 2.1, 2.2, e 2.4. Nessas relações, é a implantação das táticas de BPR que contribui para a tarefa de GC. A terceirização de atividades (2.1), a criação de parcerias (2.2) e a utilização de mercados virtuais (2.4) podem criar as condições necessárias para a eliminação de tarefas irracionais, burocráticas, ou inúteis (H2) em uma empresa.

A Tabela 2 apresenta os resultados consolidados da análise das relações entre táticas de BPR e tarefas de GC identificadas neste estudo. Pode-se observar que, como era esperado, as tarefas associadas ao capital estrutural foram as que tiveram a maior número de relações de contribuição e de indispensabilidade com as táticas de redesenho de processos. Notamos, ainda, que $60 \%$ das relações totais foram de independência, corroborando a proposição de que as metodologias de GC geralmente não abordam aspectos relacionados à formalização dos métodos de gestão do conhecimento por meio do redesenho de processos de negócio. Essa idéia é reforçada pela concentração de relações de independência nas atividades relativas ao capital humano ( $66 \%$ do total). Por outro lado, foi possível verificar que quase a metade das relações de contribuição e indispensabilidade envolve os grupos 8, 9, e 10 de táticas de BPR de El Sawy (2001). Estes grupos foram incluídos por aquele autor para incorporar a sua metodologia alguns dos princípios da Gestão do Conhecimento. Como mencionamos na introdução, tal enfoque é raro nas abordagens de redesenho de processos. Quando aqueles grupos de táticas são removidos da análise, a proporção de relações de contribuição e de indispensabilidade cai então para aproximadamente $32 \%$.

Apenas duas relações de conflito $(X)$ foram identificadas na análise. Ambas dizem respeito à tática 1.3 , que sugere que não se permita que tarefas de suporte ou gerência bloqueiem a execução do processo. A princípio, essa tática visa eliminar quaisquer interrupções no fluxo trabalho do processo que não sejam absolutamente indispensáveis ao seu objetivo final de produção de um bem ou prestação de um serviço. 
Entretanto, as tarefas $\mathrm{H} 6$ e E4 podem exigir que este fluxo seja interrompido, para a troca entre gerentes e funcionários de conhecimentos e informações associadas à visão, estratégia, valores, e cultura da empresa (H6), ou para a realização de experiências e externalização e compartilhamento conhecimentos (H7). A solução encontrada para este conflito foi simplesmente reformular a tática 1.3, para que se referisse a atividades ligadas ao acompanhamento de resultados, controle, fiscalização, sumarização, autorização e outras tarefas que não agregam valor para o cliente. Foi criada, também, outra tática de BPR, que diz: "exercer as atividades de suporte e gerência no processo de forma a facilitar a criação e o compartilhamento de conhecimento". Esta tática presume que, com o maior acúmulo de conhecimento, seja possível reduzir o tempo de espera nos processos ligados à criação de valor, mesmo que em longo prazo.

Nenhuma relação de equivalência (E) foi encontrada dentre as 456 relações analisadas. No entanto, em alguns casos, parte de uma tarefa correspondia a uma tática de BPR, ou vice-versa. Por exemplo, a criação de comunidades de prática (9.1) é uma das formas de promover a socialização do aprendizado em grupos e em equipes de trabalho (H4); e uma das formas de estimular e facilitar a colaboração com fornecedores (R2) é o estabelecimento de parcerias (2.2). Em tais casos, definimos as relações como sendo de indispensabilidade, e não de equivalência perfeita.

Tabela 2 - Consolidação dos Resultados da Análise

$\begin{array}{lll}\text { Capital } & \text { Relação } & \text { Total }\end{array}$ Conflito Indep. Contrib. Indisp. Equiv.

\begin{tabular}{|c|c|c|c|c|c|c|c|} 
Humano & 1 & 182 & 35 & 10 & 0 & 228 & $50,0 \%$ \\
\hline Estrutural & 1 & 41 & 76 & 34 & 0 & 152 & $33,3 \%$ \\
\hline Relacion. & 0 & 52 & 20 & 4 & 0 & 76 & $16,7 \%$ \\
\hline Total & 2 & 275 & 131 & 48 & 0 & 456 & $100,0 \%$ \\
\hline$\%$ & $0,4 \%$ & $60,3 \%$ & $28,7 \%$ & $10,5 \%$ & $0,0 \%$ & $100,0 \%$ & \\
\hline
\end{tabular}

Fonte: Dados da pesquisa.

\section{Adaptação de uma Metodologia de BPR}

A aplicação dos procedimentos de análise previamente descritos resultou na inclusão de tarefas de GC aos estágios da metodologia de El Sawy (2001) e na modificação de algumas de suas táticas de redesenho. Seguindo o formato geral das metodologias de BPR disponíveis na literatura (cf. KETTINGER et al., 1997), El Sawy definiu os estágios e atividades de um projeto de redesenho de processos, conforme descrito no Quadro 4. Nos próximos parágrafos, descreveremos as modificações feitas em sua metodologia. Os estágios e atividades que não são explicitamente mencionados não foram modificados. 


\section{Quadro 4 - Estágios e atividades da metodologia de El Sawy (2001)}

\begin{tabular}{|c|c|c|}
\hline \multirow[t]{2}{*}{$(1)$} & \multicolumn{2}{|c|}{ Visão executiva e inicialização } \\
\hline & $(1.1)$ & Identificação de oportunidades e necessidades de redesenho de processos \\
\hline & $(1.2)$ & $\begin{array}{l}\text { Elaboração de propostas a partir de discussões e deliberações no nível } \\
\text { gerencial }\end{array}$ \\
\hline & $(1.3)$ & Autorização do projeto de BPR pela administração executiva da empresa \\
\hline \multirow[t]{5}{*}{ (2) } & \multicolumn{2}{|c|}{ Mobilização de recursos para o projeto } \\
\hline & (2.1) & Seleção do líder do projeto e formação do time BPR \\
\hline & (2.2) & Seleção dos processos específicos a serem redesenhados \\
\hline & $(2.3)$ & Avaliação preliminar da infraestrutura de $\mathrm{TI}$ atual para esses processos \\
\hline & $(2.4)$ & Elaboração e aprovação do plano e orçamento do projeto de BPR \\
\hline \multirow[t]{8}{*}{ (3) } & \multicolumn{2}{|c|}{ Definição do escopo detalhado do projeto } \\
\hline & $(3.1)$ & Operacionalização e definição dos indicadores e metas de desempenho \\
\hline & (3.2) & Definição das fronteiras de cada processo \\
\hline & (3.3) & Identificação dos principais problemas nos processos atuais \\
\hline & (3.4) & Definição de uma visão inicial para os novos processos \\
\hline & (3.5) & Familiarização dos participantes com software de BPR \\
\hline & (3.6) & Planejamento da coleta de dados sobre os processos e seu desempenho \\
\hline & $(3.7)$ & Elaboração do relatório de escopo e do plano para a fase de modelagem \\
\hline \multirow[t]{7}{*}{ (4) } & \multicolumn{2}{|c|}{ Modelagem, análise e redefinição do processo } \\
\hline & $(4.1)$ & Realização da coleta de dados \\
\hline & $(4.2)$ & Modelagem dos processos como são atualmente ("as-is") \\
\hline & (4.3) & Análise e diagnóstico dos processos atuais \\
\hline & (4.4) & Definição de alternativas de desenho para os novos processos ("to-be") \\
\hline & $(4.5)$ & Análise e seleção das melhores alternativas \\
\hline & $(4.6)$ & Planejamento da fase de integração dos novos processos à organização \\
\hline \multirow[t]{4}{*}{ (5) } & \multicolumn{2}{|c|}{ Integração dos processos } \\
\hline & $(5.1)$ & Análise das alternativas de TI para dar suporte aos novos processos \\
\hline & $(5.2)$ & Ajuste dos processos ao contexto tecnológico e organizacional \\
\hline & $(5.3)$ & Planejamento da fase de implantação dos processos \\
\hline \multirow[t]{4}{*}{ (6) } & \multicolumn{2}{|c|}{ Implantação e transformação organizacional } \\
\hline & (6.1) & Projeto dos sistemas de informação \\
\hline & $(6.2)$ & Adequação da infraestrutura de TI \\
\hline & $(6.3)$ & $\begin{array}{l}\text { Implantação dos novos processos e das mudanças necessárias no desenho } \\
\text { organizacional, realização de treinamento do pessoal, realocação de } \\
\text { funcionários, e negociação de problemas políticos e humanos que vierem a } \\
\text { ocorrer }\end{array}$ \\
\hline (7) & \multicolumn{2}{|r|}{$\begin{array}{l}\text { Acompanhamento do desempenho dos novos processos e realização dos ajustes } \\
\text { que forem necessários }\end{array}$} \\
\hline
\end{tabular}

Fonte: Adaptado de El-Sawy (2001) 
O primeiro estágio da metodologia de El Sawy inclui a análise e revisão da estratégia da empresa e a adequação dos seus processos de negócio. Suas atividades são realizadas primariamente pela alta gerência da organização. Nesse momento, ainda não existe uma preocupação em melhorar os fluxos de trabalho, de informação e de conhecimento, nem com os aspectos operacionais mais detalhados. Desse modo, esta etapa deve também incluir a análise e definição dos objetivos e da estratégia de GC a ser adotada pela empresa e o alinhamento com sua visão e planejamento estratégico global. Uma das tarefas a ser desempenhada é, então, a identificação de competências proprietárias e/ou estratégicas para a organização (tarefa H1 de GC). É importante observar que a nova atividade e suas respectivas tarefas envolvem recursos, informações, e pessoas similares às das atividades originais de El Sawy para este estágio da metodologia. Além disso, os resultados da nova atividade de GC devem guiar a atividade de identificação das oportunidades e necessidades de redesenho de processos. Nota-se, também, que eles são necessários para a realização da tarefa H6, que deverá ser posteriormente executada. Por estas razões, a nova atividade de GC deve ser a primeira a ser realizada neste estágio da metodologia.

No terceiro estágio definido por El Sawy, é importante ajustar as atividades 3.1 , 3.2, e 3.3 para se enfoque também a perspectiva da Gestão do Conhecimento, de forma consistente com a estratégia e objetivos de GC definidos pela organização. Por conseguinte, os indicadores de desempenho e metas definidos para o processo (3.1) devem refletir os requisitos de gestão do conhecimento especificados na visão e planejamento estratégico da empresa. Eles devem, então, ser levados em conta na avaliação do desempenho do processo e levantamento dos seus problemas (3.3). As perspectivas de análise são, portanto, ampliadas com a introdução de aspectos associados à GC. Isto deve ser refletido também na definição das fronteiras do processo, que deve agora contemplar relacionamentos associados ao capital intelectual da empresa (e.g., com clientes, fornecedores, parceiros, instituições governamentais, associações, etc.), e não apenas aqueles limitados à operação rotineira das tarefas de produção de bens e prestação de serviços.

O quarto estágio na metodologia de BPR inclui as atividades de modelagem, análise e redesenho de processos. É nesta última atividade, que as táticas de redesenho listadas anteriormente (Quadro 3) são aplicadas, no sentido de melhorar os fluxos de trabalho, de informação e de conhecimento no processo. Essas atividades preocupam-se também com o alinhamento entre os processos e as tecnologias utilizadas na empresa, a estrutura organizacional e as pessoas que atuam em seus processos (e.g., suas funções e competências). Seguindo o mesmo procedimento apresentado acima, acrescentamos neste estágio várias atividades relacionadas às tarefas essenciais de GC. Elas passam, então, a ser parte integrante da análise e diagnóstico do processo atual (atividade 4.4), que agora deve incluir: (a) a análise dos fluxos de informação e de oportunidades de colaboração e troca de experiências atualmente 
existentes ao longo do processo (necessário para as próximas tarefas); (b) a identificação dos conhecimentos necessários ao desempenho das atividades do processo (tarefa $\mathrm{E} 1$ de GC; também é necessário para a tarefa R1); (c) a identificação de especialistas e outras fontes de conhecimento no processo que possam ser utilizados na criação de repositórios e diretórios de conhecimento (necessário para as tarefas $\mathrm{H} 4$, E2, E3, E4, R1, R2); (d) a criação de mapas de competência para as pessoas envolvidas no processo (necessário para a tarefa $\mathrm{H3}$ ); (e) a análise das necessidades de informação de outros setores da empresa que interajam com o processo (necessário para a tarefa R1); e (f) a análise do acesso dos clientes ao processo e das informações que precisam (necessário para a tarefa R2). Vale ressaltar que tais atividades exigirão a coleta de informações específicas, e que, por isso, as atividades de planejamento e coleta de dados (3.6 e 4.1) devem ser ajustadas para refletir estas necessidades.

Com a adição das atividades acima, a análise e diagnóstico do processo atual passaram a considerar também aspectos relativos à gestão do capital intelectual da empresa. O próximo passo é a elaboração de alternativas de melhoria para o processo, levando em conta também os aspectos de GC. Dessa forma, algumas tarefas passaram a integrar a atividade de definição de alternativas para o novo processo (4.4): (a) a criação de comunidades de prática compostas para os grupos de pessoas com interesses afins no processo (tarefa $\mathrm{H} 4$ ); (b) $\mathrm{O}$ uso de times multifuncionais para realizar, quando possível, as atividades do processo (tarefa $\mathrm{H} 4$ ); e (c) a definição de atividades específicas durante o processo para a troca de informações e experiências e a externalização, codificação, validação, e transferência de conhecimentos, não só para os membros da organização, como também entre estes e os fornecedores e clientes do processo (tarefas H4, H6, E3, E4, R1, R2).

No estágio de integração dos processos, os componentes de tecnologia e as atividades do novo processo são alinhados entre si. Adicionamos a este estágio, portanto, uma tarefa que visa incorporar às atividades do processo os diversos tipos de sistemas de gestão de conhecimento baseados em computadores (Knowledge Management Systems (KMS)) (e.g., ALAVI; LEIDNER, 2001; DUFFY, 2001; SMITH; MCKEEN, 2004) que dão suporte e agilizam a criação, armazenagem/recuperação, transferência e aplicação de conhecimentos. Esta nova tarefa está relacionada às tarefas E2, E3, e E4 de GC, anteriormente definidas.

O sexto estágio da metodologia de El Sawy refere-se à implantação e transformação organizacional. É, nesta fase, que efetivamente ocorre a implementação dos novos processos de negócio, bem como a execução de todas as outras iniciativas para ajustar as diversas variáveis organizacionais a cada novo processo. Tais iniciativas incluem a formação das equipes de trabalho, a introdução de programas de treinamento, a modificação de sistemas de avaliação de desempenho e de remuneração, a transformação da estrutura organizacional e a implantação de novos sistemas de informação e tecnologias necessárias para a perfeita 
execução dos processos. Com base nisso, foi necessário incorporar novas tarefas de GC à atividade 6.3, a saber: (a) desenvolver e implantar programas de treinamento e desenvolvimento profissional orientados pelas necessidades de conhecimento no processo e mapas de competências das pessoas que nele estão envolvidas (tarefa H3 de GC); (b) introduzir métodos de acompanhamento da evolução dos profissionais, de forma a manter atualizados os seus mapas de competência (relacionado às tarefas $\mathrm{H3}$ e $\mathrm{H} 5$ ); modificar, quando necessário, os métodos de avaliação de desempenho, incentivos e remuneração, para que reflitam os objetivos de geração, transferência e aplicação de conhecimentos (tarefa H5); (c) criar, quando necessário, programas de rotação de pessoal, visitas, e de integração de setores da empresa, parceiros, fornecedores e clientes, para estimular o desenvolvimento profissional, a construção de relacionamentos e a troca de experiências, informações, e de conhecimentos (tarefas H4, H5, R1, R2); (d) instituir as funções de integrador e de facilitador para estimular o compartilhamento de conhecimentos e resolver os conflitos que por ventura vierem a ocorrer (NONAKA, 1991) (necessário para as tarefas H4, H6, E3, R1, R2); e (e) desenvolver um programa de parcerias com clientes, fornecedores $\mathrm{e}$ outras organizações, visando fomentar o desenvolvimento conjunto e a transferência de conhecimentos (tarefa R2). Deve-se ressaltar que os ajustes associados à infraestrutura tecnológica e à estrutura e cultura organizacionais já eram contemplados nas atividades originais deste estágio.

Por fim, no sétimo estágio, ajustaram-se as atividades de acompanhamento do desempenho do processo para que incluíssem a avaliação e medição do acúmulo de capital intelectual utilizado, gerido, e criado em seu contexto. Embora haja vários métodos propostos para este fim na literatura (e.g., EDVINSSON; MALONE, 1998), sua discussão foge ao escopo do presente trabalho.

\section{Conclusão}

Os conhecimentos gerados e obtidos através dos métodos de GC adicionam valor a um negócio apenas na medida em que são traduzidos em ações alinhadas aos objetivos estratégicos da organização. Os processos de negócio desempenham, então, um papel fundamental na concretização dos benefícios e do valor esperado das iniciativas de GC (SMITH; MCKEEN, 2004; SEELEY, 2002). Nesse sentido, o presente trabalho contribui para a sistematização e formalização da integração dos princípios e técnicas da Gestão do Conhecimento às atividades de redesenho de processos. As modificações da metodologia de BPR que foram sugeridas permitem que os novos processos desenhados em projetos desse tipo incorporem uma série de tarefas que, quando adequadamente realizadas, põem em prática os conceitos de GC frequentemente encontrados na literatura. Dessa forma, a proposta aqui apresentada dá suporte à "definição de práticas formais que promovam interações e trocas e melhorem a transferência de conhecimento, na 
medida em que definem explicitamente oportunidades para os colaboradores de uma empresa compartilharem know-how e know-why entre si" (PATNAYAKUNI; RUPPEL; RAI 2006, p. 561). Espera-se assim que a aplicação da metodologia revisada promova a adequada integração e otimização dos elementos organizacionais e um melhor aproveitamento dos recursos intangíveis da empresa.

As análises realizadas em nosso estudo dão suporte à ideia de que as metodologias de GC e BPR tradicionalmente empregadas pelas empresas têm poucos pontos em comum. No entanto, as incompatibilidades e conflitos, pelo menos nos casos que analisamos, foram poucos, o que permitiu a integração das duas abordagens. Esse resultado se contrapõe ao argumento de Scarbrough (1998), de que BPR apresenta características que são inerentemente conflitantes com a adoção efetiva da GC, a saber: (1) o privilégio de competências mais abrangentes, em detrimento da especialização; (2) o encorajamento de uma visão de curto prazo, focada em eficiência operacional e no atendimento das necessidades imediatas dos clientes; (3) o estímulo à redução da força de trabalho, que tipicamente gera perdas de capital intelectual; e (4) a promoção de alterações radicais em processos, regras de negócio, e estruturas organizacionais que cristalizam o conhecimento acumulado na organização. Na medida em que a metodologia aqui proposta inclui etapas de análise das competências críticas para o negócio e de alinhamento entre as estratégias corporativa e de GC da empresa, reduz-se o risco de adoção de alternativas de redesenho de processo que gerem perdas significativas de ativos intangíveis importantes. Além disso, as alterações feitas na terceira e quarta etapas da metodologia de El Sawy (2001) garantem que o novo processo incorpore atividades de geração, registro, transmissão e reutilização de conhecimentos essenciais para o negócio, sejam eles abrangentes ou especializados. Da mesma forma, elas criam mecanismos para a proteção dos elementos do sistema organizacional que representem ativos significantes de conhecimento, tais como estruturas e regras de negócio, relacionamentos, práticas de trabalho e, até mesmo, grupos e indivíduos que detenham conhecimentos tácitos fundamentais para o sucesso da empresa.

A análise e os resultados descritos nesta pesquisa revelam também possibilidades interessantes de investigação sobre a aproximação da GC à visão de processos. Por exemplo, estudos de caso poderiam ser conduzidos para validar a metodologia proposta em vários tipos de organização e processos. Essas pesquisas permitiram, por exemplo, a identificação de barreiras de implantação e fatores críticos de sucesso, a medição de custos e a avaliação de benefícios, e a definição de pontos nas duas abordagens que ainda requerem uma maior convergência. Tais estudos estariam em linha com a recomendação de Silva e Rozenfeld (2007, p. 156), de que se investigue a inclusão de práticas de GC em diferentes tipos de processo.

Espera-se, também, que o acúmulo de evidências empíricas e conhecimentos sobre os temas aqui tratados dê suporte à elaboração de modelos que relacionem antecedentes, características e resultados de 
uma revisão de processos integrada às práticas de gestão do conhecimento. No entanto, embora já haja na literatura algumas propostas de escalas quantitativas para a mensuração de aspectos relacionados a práticas de CG (e.g., PATNAYAKUNI; RUPPEL; RAI, 2006), trabalhos nos quais são adotadas são raros, não havendo, ainda, consenso quanto à melhor forma de avaliação dos construtos correspondentes. Novos estudos nessa linha não poderiam deixar de lado a busca por definições consistentes dos domínios dos referidos construtos - passo indispensável para que se possa acumular conhecimento e evidências científicas sobre qualquer fenômeno.

Por fim, vale ainda destacar a potencial contribuição advinda do desenvolvimento dos procedimentos de análise e integração apresentados neste estudo. Não foi possível encontrar na literatura de Administração uma metodologia que apoiasse a avaliação e desenvolvimento de metodologias. Acreditamos, assim, que os procedimentos aqui descritos constituam um passo inicial nessa direção. Pesquisas futuras poderiam avaliar sua aplicabilidade à integração de outras metodologias de implantação de modelos de gestão. Além disso, tais análises poderiam ter por base a visão conjunta de vários especialistas, obtida por meio do uso de grupos focais. Dessa forma, a validade das conclusões geradas poderia ser substancialmente melhorada.

\section{Referências}

ALAVI, M.; LEIDNER, D. E. Review: gestão do conhecimento and gestão do conhecimento systems: conceptual foundations and research issues, MIS Quarterly, v. 25, n. 1, p. 107-132, 2001.

BALDAN, R. L. et al. O Ciclo do gerenciamento de processos de negócio: proposta prática. In:__. Gerenciamento de processos de negócios: BPM - Business Process Management. 2 ed. São Paulo: Érica, 2007.

CRUZ, T. BPM \& BPMS: Business Process Management \& Business Process Management Systems. Rio de Janeiro: Brasport, 2008.

DANE, F. C. Research methods. Pacific Grove, CA: Brooks/Cole Publishing Company, 1990.

DAVENPORT, T. H. Process innovation: reengineering work. Boston: Harvard Business School, 1993.

DAVENPORT, T. H.; PRUSAK, L. Working knowledge: how organizations manage what they know. Boston: Harvard Business School, 1998.

DAVENPORT, T. H.; SHORT, J. E. The new industrial engineering: information technology and business process redesign. Sloan Management Review, Summer, p. 111-27, 1990.

DE SORDI, J. O. Gestão por processos: uma abordagem da moderna administração. São Paulo: Saraiva, 2005. 
DUFFY, J. The tools and technologies needed for gestão do conhecimento. Information Management Journal, v. 35, n. 1, p. 64-67, 2001.

EDVINSSON, L.; MALONE, M. Capital intelectual: descobrindo o valor real de sua empresa pela identificação de seus valores internos. São Paulo: Makron Books, 1998.

EL SAWY, O. A. Redesigning enterprise processes for e-business. Nova York: Irwin/McGraw-Hill, 2001.

EL SAWY, O.; JOSEFEK, R. Business process as nexus of knowledge. Handbook on Knowledge Management, Berlin, v. 1, p. 425-438, SpringerVerlag 2003.

GARVIN, D. A. Building a learning organization. Harvard Business Review, v. 71, n. 4, p. 78-91, 1993.

GONÇALVES, J. E. L. Processo, que processo? RAE - Revista de Administração de Empresas, v. 40, n. 4, p. 8-119, 2000.

HAMMER, M. Reengineering work: don't automate, obliterate. Harvard Business Review, v. 68, n. 4, p. 104-112, 1990.

HAMMER, M.; CHAMPY, J. Redesenho: revolucionando a empresa em função dos clientes, da concorrência e das grandes mudanças da gerência. Tradução de Ivo Korytovsky. 28 ed. Rio de Janeiro: Campus, 1994.

HAMMER, M.; STANTON, S. How process enterprises really work. Harvard Business Review, v. 77, n. 6, p. 108-118, 1999.

HARRINGTON, H. J. Business process improvement: the breakthrough strategy for total quality, productivity, and competitiveness. New York: Mc Graw-Hill, 1991.

INSINGA, R. C.; WERLE, M. J. Linking outsourcing to business strategy. Academy of Management Executive, v. 14, n. 4, p. 58-70, 2000.

KETTINGER, W. J.; TENG, J. T. C.; GUHA S. Business process change: a study of methodologies, techniques, and tools. MIS Quarterly, v. 21, n. 1, p. 55-80, 1997.

LAURINDO, F. J. B.; ROTONDARO, R. G. Unindo tecnologia da informação e gestão por processos: introdução e objetivos. In: (Coord.). Gestão integrada de processos e da tecnologia da informação. São Paulo: Atlas, 2006, p. 1-13.

NONAKA, I. The knowledge-creating company. Harvard Business Review, v. 69, n. 6, p. 96-104, 1991.

NONAKA, I. A dynamic theory of organizational knowledge creation. Organization Science, v. 5, n. 1, p. 14-37, 1994.

OLIVEIRA, A. M. A. et al. Avaliação de ferramentas de Business Process Management (BPMS) pela ótica da gestão do conhecimento. Perspectivas em Ciência da Informação, v. 15, n. 1, p. 132-153, 2010. 
OLIVEIRA, R. B. C. D. Uma metodologia de modelagem de processos de negócio orientada à gestão da informação e do conhecimento. Perspectivas em Ciência da Informação, 2010. Disponível em: < http://www.bibliotecadigital.ufmg.br/dspace/bitstream/1843/ECID7X9JJ9/1/dissertacao rafael oliveira.pdf >. Acesso em: 10/05/2011.

PATNAYAKUNI, R.; RUPPEL, C. P.; RAI, A. Managing the complementarity of knowledge integration and process formalization for systems development performance. Journal of the Association for Information Systems, v. 7, n. 8, p. 545-567, 2006.

POLANYI, M. The tacit dimension. London: Routledge \& Kegan Paul, 1966. RIEGE, A.; O'KEEFFE, M. Intra-organisational Knowledge Drivers in the INPD Process: the case of wattyl limited. International Journal of Innovation Management, v. 11, n. 3, p. 349-378, 2007.

RUMMLER, G. A.; BRACHE, A. P. Melhore o desempenho das empresas. São Paulo: Makron Books, 1994.

SCARBROUGH, $\mathrm{H}$. BPR and the knowledge-based view of the firm. Knowledge and Process Management, v. 5, n. 3, p. 192-200, 1998.

SEELEY, C. Igniting knowledge in your business processes. KM Review, v. 5, n. 4, p. 12-15, 2002.

SILVA, F. P. C; PEREIRA, N. A. Modelagem de processos de negócios na implementação de ERPs nacionais em PMEs. Produção, v. 16, n. 2, p. 341352, maio/ago. 2006.

SILVA, S.; ROZENFELD, H. Proposição de um modelo para avaliar a gestão do conhecimento no processo de desenvolvimento de produtos. Ciência e Informação, Brasília, v. 36, n. 1, p. 147-157, 2007.

SMITH, H. A.; MCKEEN, J. D. Developments in practice XII: knowledgeenabling business processes. Communications of the Association for Information Systems, v. 13, p. 25-38, 2004.

STEWART, T. Capital intelectual. Rio de Janeiro: Campus, 1998.

SVEIBY, K. E. A nova riqueza das nações. 6 ed. Rio de Janeiro: Campus, 1998.

ZACK, M. H. Rethinking the knowledge-based organization. MIT Sloan Management Review, v. 44, n. 4, p. 67-71, 2003. 